\title{
IDOSO EM SITUAÇÃO DE ABANDONO E CONDUTA DE ENFERMAGEM
}

\section{REVISÃO INTEGRATIVA}

SILVA, Jânio Reis da ${ }^{1}$

CAMARGO, Elaine de ${ }^{2}$

SANTOS, Rodrigo Rocha dos ${ }^{3}$

SANTOS, Sara Noemy Araújo dos ${ }^{4}$

PIOTO, Marcela Rocha ${ }^{5}$

SILVA, Jânio Reis da. Et al. Idoso em situação de abandono e conduta de enfermagem. Revista Científica Multidisciplinar Núcleo do Conhecimento. Ano 04, Ed. 10, Vol. 13, pp. 166-182. Outubro de 2019. ISSN: 2448-0959, Link de acesso: https://www.nucleodoconhecimento.com.br/saude/situacao-de-abandono

\section{RESUMO}

Devido ao processo de envelhecimento e aumento de pessoas vivendo na terceira idade, decorre-se a incidência de doenças crônicas e do mesmo modo, o tempo de cuidados e internações em hospitais. Mesmo sendo obrigação legal da família cuidar de quem envelhece, o dever moral e afetivo por motivos distintos, não considerados,

\footnotetext{
${ }^{1}$ Graduando de Enfermagem.

2 Graduando de Enfermagem.

${ }^{3}$ Graduando de Enfermagem.

${ }^{4}$ Graduando de Enfermagem.

${ }^{5}$ Mestrado em andamento em Ciências da Saúde. Especialização em Formação de Docentes de Enfermagem em Nível Técnic. Especialização em Enfermagem em Urgência e Emergência. Graduação em Enfermagem.
} 
acaba provocando alterações psíquicas e elevações nos problemas de saúde. O indivíduo idoso por diversas ocasiões se descobre em um cenário de descuido familiar perante as complicações que a velhice impõe. Este estudo tem por principal meta identificar e analisar a relevância das atividades da enfermagem focada na população idosa, em circunstância de descaso familiar, segundo a literatura. Assim, decorreu por revisão integrativa a exploração de artigos divulgados em bases de dados Lilacs e na biblioteca Scielo. Em âmbito hospitalar, a idade pode ser considerada fator indicativo, determinante em apoio ao idoso enfermo, como parâmetro fidedigno que estabelece critérios específicos de atendimento. A retomada da ética em uma visão ampla sobre o envelhecimento gera porfias, principalmente na enfermagem que busca promover uma assistência integra e humanizada ao idoso.

Descritores: Idoso, abandono de idosos, cuidados de enfermagem, atenção integral ao idoso, enfermagem.

\section{INTRODUÇÃO}

Envelhecer é um processo definido por várias etapas: nascimento, desenvolvimento, puberdade, maturidade e envelhecimento, cada uma dessas fases tem sua diferença específica e se unificam ao longo da vida (ABREU et al., 2015).

Conforme os dados do IBGE, em 2015 havia no Brasil 20,5 milhões de pessoas idosas, por volta de 39 para cada 100 jovens. A previsão para 2040 é quase o triplo, de aproximadamente 153 pessoas idosas para cada 100 jovens. É patente que a quantidade de idosos é progressiva, estendendo assim às demandas atuais e futuras, o que pode gerar uma sobrecarga no sistema e saúde (MIRANDA et al., 2016).

Aproximadamente $14 \%$ da população brasileira encontra-se acima de 60 anos. Em 2060 pressupõe o IBGE uma inversão entre jovens e idosos. As informações estão representadas no gráfico 1 abaixo (SILVA, 2016).

O processo de envelhecer vem sendo debatido e cercado de intervenções que visam acastelar a população idosa, que ao transcorrer dos anos se alteia. Os idosos em 
1970, auferiam auxílio sobretudo de organizações não governamentais e religiosas, semelhantes as atividades filantrópicas. No que tange a legislação, no século XX os idosos foram abordados no código civil, penal e eleitoral, incluindo decretos e portarias correlacionadas principalmente com questões de aposentadoria, além de ter estabelecido um benefício vitalício pela Lei № 6.179 de 1974. (RODRIGUES et al, 2013).

A população em geral vem, ao longo dos tempos, aumentando sua expectativa de vida, fazendo assim, com que pessoas vivam a terceira idade por mais tempo. Ao mesmo tempo, existe a propensão do surgimento de doenças crônicas, característico do envelhecimento e alta probabilidade de hospitalização. Tais degenerações crônicas são estipuladas como conjuntura comumente incuráveis, requisitando uma adaptação singular que tenciona precaver, diminuir ou moderar as adversidades em longo prazo (OLIVEIRA et al., 2016).

Com o envelhecimento, surge redução das atividades metabólicas do organismo, que dispõe de alguns aspectos correlacionados a enfermidades, resultando de modo contínuo na elaboração de atividades governamentais internacionais e nacionais, voltadas para os trabalhadores de saúde e essencialmente aos idosos. Assim, é apurado a elevação da quantidade de idosos na população, em consequência do declínio da natalidade, esperança de vida e do progresso da tecnologia, que permitiu a realização de intervenções em situações antes inviáveis (VERAS et al., 2013).

As doenças crônicas estão relacionadas com a elevação da esperança de vida, sucedendo diversas incapacidades e limitações nos idosos. Assim, a prevenção de doenças e os cuidados à saúde da população idosa, representam novos desafios para a enfermagem e saúde pública (CARRETA et al., 2011).

Quando a capacidade funcional diminui na pessoa idosa, acaba por implicar em prejuízos para o próprio indivíduo e seu familiar, afetando o sistema de saúde e à vida do próprio idoso, pois provoca maior vulnerabilidade e dependência, podendo contribuir para a diminuição da qualidade de vida (VERAS; OLIVEIRA, 2016). 
Repercussões negativas podem surgir na vida da pessoa idosa, quando além dos limites físicos, os emocionais atinjam o cotidiano desse indivíduo, que é acarretado pela perda do status ocupacional e econômico, declínio físico continuado, maior frequência de doenças físicas e a incapacidade, que em períodos a diante, ostenta o engajamento rígido dos níveis cognitivos rente a submissão absoluta. (SANTANTA NETO, 2013; NASCIMENTO, 2019).

A ausência de ternura por outro indivíduo é capaz de acontecer, independentemente do tipo de relação exercida, o respeito mútuo é uma obrigação. A família tem a responsabilidade de tutelar e confortar o idoso (VIEGAS; BARROS, 2016).

No âmbito jurídico, a constituição brasileira de 1988, declara que os filhos quando maior de idade possui como obrigação, tutelar e amparar seus progenitores em condição de senilidade, carência ou de debilidade. O compromisso de zelo com o idoso, é, deste modo, um dever. Não obstante, o fato ser uma obrigação os filhos zelarem por seus pais, existe inclusive a obrigação ética e devotada, que por vezes não tem sido respeitada, gerando transtornos psíquicos e agravamento de doenças (VIEGAS; BARROS, 2016).

Mesmo sendo uma obrigação legal, os filhos cuidarem de seus pais idosos, o que se observa é exatamente o contrário, na área social e da saúde, é cada vez mais comum que essas pessoas sejam abandonadas à própria sorte. Assim sendo, surge como problema de pesquisa: como se dá a assistência e o cuidado do enfermeiro à pessoa idosa, sobretudo no que tange ao rastreio de abandono dessa população?

O idoso por diversos instantes se depara em um estado de abandono familiar diante das complicações que a velhice impõe. A ascensão do envelhecimento indulgente, requer modificações nas metas e nos afazeres, integrando conforto de vida.

A população idosa corresponde a um amplo percentual dos utentes dos sistemas de saúde, recorrendo particularmente das atividades de enfermagem. Todo esse processo impõe atenção específica dos programas de saúde de idosos em todos os lugares, ressalta-se a importância da capacitação dos profissionais, oferecendo-Ihes 
uma maior autonomia a fim de melhorar a assistência humanizada ao idoso em situação de abandono.

\section{OBJETIVO}

Identificar, na literatura, idosos em situação de abandono referidos pelos integrantes da equipe de enfermagem e analisar a relevância da assessoria de enfermagem a esta população, segundo a literatura.

\section{MÉTODO}

Tratou-se de uma revisão integrativa, que se caracteriza por análise extensa da literatura a respeito de um tema em particular, com propósito, arquitetar uma composição de estudos efetuados isoladamente, investigando problemas iguais ou equivalente (LAKATOS; MARCONI, 2011).

Se utilizou a seguinte questão norteadora: como é a assistência da equipe de enfermagem ao idoso em situação de abandono?

A busca foi realizada na Biblioteca Virtual de Saúde, Scientific Electronic Library Online, (SciELO), biblioteca BIREME, e nas bases de dados Literatura Latinoamericana e do Caribe em Ciências da Saúde (LILACS), que reúne as publicações científicas da área da Saúde da América Latina e do Caribe; National Library of Medicine (MEDLINE) e Portal de Evidências, o qual oferece acesso integrado a fontes de informação em saúde de melhor nível de evidência científica.

As palavras-chave para a coleta de dados foram selecionadas a partir dos Descritores de Ciências de Saúde (Decs), sendo: Idoso; Abandono de Idosos; Cuidados de Enfermagem; Atenção Integral ao Idoso; Enfermagem. A partir destas palavras foi utilizado o ligador booleano AND.

Os parâmetros de inserção dos artigos foram determinados deste modo: ser artigo de averiguação difundido em periódicos nacionais, listado em bases de dados e publicado entre 2010 e 2019. 
Os critérios de eliminação, foram artigos divulgados fora do intervalo de 2010 a 2019, que estiverem disponíveis somente o resumo, publicados em outra língua que não a portuguesa.

No decorrer da pesquisa e estudo dos artigos, encontrados foram, 359 artigos e designadas 17 publicações, que consideraram os desígnios propostos, sendo excluídos os que na leitura do tema não apresentavam relação com o tema da pesquisa.

Para sinopse e avaliação dos artigos, foram empreendidos os imediatos processos: leitura exploratória, seletiva, crítica e reflexiva.

Para seleção dos artigos científicos considerou-se artigos que abordam os descritores propostos onde observamos se possuem relação de interesse do título (rastreio de idoso em situação de abandono e conduta de enfermagem).

Foram descartados textos resumidos que não permitem acesso na integra, artigos que não atendam o objetivo proposto e ano de publicação superior há 9 anos que não estejam disponíveis na integra.

\section{RESULTADOS}

Rastreando estudo das referências e dos conteúdos examinados nos artigos, estes foram ordenados conforme ano, base de dados, título, métodos e principais resultados.

Foram detectados, por meio dos descritores recorridos, 45 artigos na BVS, 15 dos artigos se localizam na base de dados da LILACS, os demais na CAPES e SCIELO. Após examinar e acatar, precisamente, os parâmetros de inserção e eliminação, já especificados na metodologia, designados foram 20 artigos divulgados entre 2010 a 2019, sobre abandono de idosos.

A representação dos artigos designados para o presente estudo está na tabela 1 abaixo. 
Tabela 1 - Descrição dos artigos segundo ano, título do artigo, método, principais resultados. São Paulo, 2019.

\begin{tabular}{|c|c|c|c|c|}
\hline 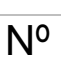 & Autor, ano & ítulo & Método & Principais resultados \\
\hline 1 & LINO et al, 2019 & $\begin{array}{l}\text { Prevalência e } \\
\text { fatores associados } \\
\text { ao abuso de } \\
\text { cuidadores contra } \\
\text { idosos } \\
\text { dependentes: a } \\
\text { face oculta da } \\
\text { violência familiar }\end{array}$ & $\begin{array}{l}\text { Estudo } \\
\text { transversal }\end{array}$ & $\begin{array}{l}\text { A alta predominância } \\
\text { de negligências } \\
\text { praticada pelos } \\
\text { cuidadores, que } \\
\text { indicam elevada } \\
\text { sobrecarga e estresse } \\
\text { e, infortúnios } \\
\text { associados ao álcool, } \\
\text { que necessitam de } \\
\text { suporte familiar. }\end{array}$ \\
\hline 2 & $\begin{array}{l}\text { NASCIMENTO } \\
\text { HG, } \\
\text { FIGUEIREDO } \\
\text { AE. } 2019\end{array}$ & $\begin{array}{l}\text { Demência, } \\
\text { familiares } \\
\text { cuidadores } \\
\text { serviços de saúde: } \\
\text { o cuidado de si e do } \\
\text { outro }\end{array}$ & $\begin{array}{l}\text { Pesquisa } \\
\text { qualitativa } \\
\text { analítica- } \\
\text { descritiva }\end{array}$ & $\begin{array}{l}\text { Para cuidadores que } \\
\text { são da família, o que } \\
\text { exacerba } \\
\text { dificuldades no } \\
\text { cuidado é a estado de } \\
\text { descaso que eles } \\
\text { vivenciaram. }\end{array}$ \\
\hline 3 & $\begin{array}{l}\text { NUNES, } \\
\text { PACHECO. } \\
2018\end{array}$ & $\begin{array}{l}\text { O processo saúde } \\
\text { doença da pessoa } \\
\text { idosa em situação } \\
\text { de abandono }\end{array}$ & $\begin{array}{l}\text { Pesquisa } \\
\text { social } \\
\text { qualitativa }\end{array}$ & $\begin{array}{l}\text { O estudo expõe o } \\
\text { perfil da população } \\
\text { idosa em estado de } \\
\text { violência } \\
\text { evidenciam que } \\
\text { fragilidade social, o } \\
\text { abandono destacou- } \\
\text { se sendo a negligência } \\
\text { mais experimentada } \\
\text { por essa população. }\end{array}$ \\
\hline
\end{tabular}




\begin{tabular}{|c|c|c|c|c|}
\hline 4 & $\begin{array}{l}\text { SANGUINO, } \\
\text { G.Z. } 2018 .\end{array}$ & $\begin{array}{l}\text { O trabalho de } \\
\text { enfermagem ao } \\
\text { idoso hospitalizado }\end{array}$ & $\begin{array}{l}\text { Pesquisa } \\
\text { exploratória } \\
\text { descritiva }\end{array}$ & $\begin{array}{l}\text { A atenção dada pela } \\
\text { enfermagem ao idoso } \\
\text { internado, exige } \\
\text { cautela, pois é } \\
\text { facilmente elaborado } \\
\text { visando agilidade dos } \\
\text { profissionais. }\end{array}$ \\
\hline 5 & $\begin{array}{l}\text { LIKES, S.A. et } \\
\text { al. } 2018\end{array}$ & $\begin{array}{l}\text { Estatuto do idoso e } \\
\text { sua aplicabilidade: } \\
\text { o cuidado de } \\
\text { enfermagem em } \\
\text { uma Estratégia } \\
\text { Saúde da Família }\end{array}$ & $\begin{array}{l}\text { Estudo de } \\
\text { natureza } \\
\text { qualitativa }\end{array}$ & $\begin{array}{l}\text { Foi presenciado a } \\
\text { preocupação dos } \\
\text { enfermeiros em } \\
\text { estimular e exercer a } \\
\text { rede de apoio, dando } \\
\text { ênfase ao Estatuto do } \\
\text { Idoso. }\end{array}$ \\
\hline 6 & $\begin{array}{l}\text { LOPES, E.D.S. } \\
\text { et al. } 2018\end{array}$ & $\begin{array}{l}\text { Maus tratos a } \\
\text { idosos no Brasil }\end{array}$ & $\begin{array}{l}\text { Revisão } \\
\text { Integrativa }\end{array}$ & $\begin{array}{l}\text { As agressões que se } \\
\text { destacaram foram as } \\
\text { psicológicas, } \\
\text { agregada as físicas, } \\
\text { sendo as que essas, } \\
\text { ocorrendo na maior } \\
\text { parte nas mulheres. }\end{array}$ \\
\hline 7 & $\begin{array}{l}\text { VIEGAS LM, } \\
\text { FERNANDES } \\
\text { AA, VEIGA } \\
\text { MAPL } 2018\end{array}$ & $\begin{array}{lr}\text { Intervenção de } & \text { de } \\
\text { enfermagem } & \text { no } \\
\text { estresse } & \text { do } \\
\text { cuidador familiar do } & \\
\text { idoso com } & \\
\text { dependência: } & \\
\text { estudo piloto }\end{array}$ & Estudo piloto & $\begin{array}{l}\text { Verificou-se } \\
\text { aprimoramentos no } \\
\text { coping, no conforto e } \\
\text { no excesso de } \\
\text { trabalho. }\end{array}$ \\
\hline 8 & $\begin{array}{l}\text { ARAÚJO } \\
\text { NETO, A.H et al. } \\
2017\end{array}$ & $\begin{array}{l}\text { Quedas em idoso } \\
\text { institucionalizados: } \\
\text { riscos, }\end{array}$ & $\begin{array}{l}\text { Revisão } \\
\text { bibliográfica }\end{array}$ & $\begin{array}{l}\text { Retratou ocorrências } \\
\text { de quedas e contribuiu } \\
\text { para um tratamento }\end{array}$ \\
\hline
\end{tabular}




\begin{tabular}{|c|c|c|c|c|}
\hline & & $\begin{array}{l}\text { consequências e } \\
\text { antecedentes. }\end{array}$ & & $\begin{array}{l}\text { focado e humanizado } \\
\text { ao idoso. }\end{array}$ \\
\hline 9 & $\begin{array}{l}\text { PERSEGUINO } \\
\text { MG, HORTA } \\
\text { ALM, RIBEIRO } \\
\text { CA. }\end{array}$ & $\begin{array}{l}\text { A família frente a } \\
\text { realidade do idoso } \\
\text { de morar sozinho }\end{array}$ & $\begin{array}{l}\text { Abordagem } \\
\text { qualitativa, } \\
\text { com } \\
\text { referencial } \\
\text { teórico }\end{array}$ & $\begin{array}{l}\text { A enfermagem, } \\
\text { incumbida por } \\
\text { preparar métodos de } \\
\text { como cuidar, tem por } \\
\text { dever executar seu } \\
\text { trabalho ligado às } \\
\text { famílias e auxilia-las } \\
\text { no delineamento de } \\
\text { planos integrais. }\end{array}$ \\
\hline 10 & $\begin{array}{l}\text { MENEZES } \\
\text { JUNIOR et al. } \\
2016 .\end{array}$ & $\begin{array}{l}\text { Caracterização do } \\
\text { Abandono Afetivo } \\
\text { do idoso e as } \\
\text { ações em Anápolis } \\
\text { de apoio ao dever } \\
\text { da proteção } \\
\text { integral: proposta } \\
\text { de construção de } \\
\text { cartilha informativa } \\
\text { à terceira idade }\end{array}$ & $\begin{array}{l}\text { Estudo } \\
\text { teórico } \\
\text { observacional }\end{array}$ & $\begin{array}{l}\text { É imprescindível a } \\
\text { conservação do } \\
\text { empenho necessário } \\
\text { para garantir os } \\
\text { benefícios dos idosos, } \\
\text { estabelecendo, assim, } \\
\text { normas que buscam } \\
\text { contribuir e diminuir as } \\
\text { desigualdades } \\
\text { aturadas por essa } \\
\text { população. }\end{array}$ \\
\hline 11 & $\begin{array}{l}\text { CAMACHO, } \\
\text { A.C.L.F.; } \\
\text { ALVES, R.R. } \\
2015 .\end{array}$ & $\begin{array}{l}\text { Maus tratos contra } \\
\text { os idosos na } \\
\text { perspectiva }\end{array}$ & $\begin{array}{l}\text { Revisão } \\
\text { Integrativa }\end{array}$ & $\begin{array}{l}\text { A bibliografia } \\
\text { apresenta que há } \\
\text { diversos } \\
\text { trabalhadores na área } \\
\text { da saúde } \\
\text { despreparados quanto } \\
\text { a assistência ao idoso } \\
\text { vítima de } \\
\text { abandono/negligência }\end{array}$ \\
\hline
\end{tabular}




\begin{tabular}{|c|c|c|c|}
\hline $\begin{array}{l}2 \text { GASPAROTTO, } \\
\text { L. P. R. et al. } \\
2014 .\end{array}$ & $\begin{array}{l}\text { As quedas no } \\
\text { cenário da velhice: } \\
\text { conceitos básicos e } \\
\text { atualidades da } \\
\text { pesquisa em saúde }\end{array}$ & $\begin{array}{l}\text { Revisão } \\
\text { bibliográfica }\end{array}$ & $\begin{array}{l}\text { apoio } \\
\text { multidisciplinar está } \\
\text { baseado na prevenção } \\
\text { de quedas e carece de } \\
\text { conhecimentos } \\
\text { especializados dos } \\
\text { profissionais que } \\
\text { zelam pelo idoso. }\end{array}$ \\
\hline $\begin{array}{l}\text { SOUSA, } \\
\text { RIBEIRO, } \\
\text { A.P.2013. }\end{array}$ & $\begin{array}{l}\text { Prestar cuidados } \\
\text { de enfermagem a } \\
\text { pessoas idosas: } \\
\text { experiências e } \\
\text { impactos }\end{array}$ & $\begin{array}{l}\text { Estudo } \\
\text { exploratório }\end{array}$ & $\begin{array}{lr}\text { A doença } & \text { e } \\
\text { dependência } & \text { de } \\
\text { pessoas } & \text { idosas } \\
\text { trazem uma reflexão } \\
\text { nos enfermeiros sobre } \\
\text { sua } \\
\text { profissional } \\
\text { aumentando } \\
\text { compaixão. }\end{array}$ \\
\hline
\end{tabular}

Fonte: Autoria própria.

\subsection{DISCUSSÃO}

O envelhecimento é um evento integrado a vida, considerado hoje como um fator mundial, ocasionado, comumente, por condições de vida melhorada, evolução da medicina e da tecnologia, realização de exercícios físicos e dieta equilibrada, acarretando, consequentemente, elevação da expectativa de vida (GASPAROTTO e SANTOS, 2013).

A representação que a sociedade dissemina, a respeito do idoso, ainda carrega marcas do declínio físico da incapacidade, o que amplia a decadência mental e social de algum tempo atrás, o prolongamento da longevidade acarreta diversas dificuldades para o cuidado ao paciente idoso (GASPAROTTO e SANTOS, 2013). 
Envelhecer é um processo definido por várias etapas que se consolidam no decorrer da vida. A partir de sua fecundação, o ser humano trespassa por diversos ciclos em seu desenvolvimento. Após o nascimento, o indivíduo cresce, atinge a puberdade, maturescência e alcança a velhice. Parece uma divisão simples, mas cada uma dessas fases possui diferenças significativas (ILHA et al., 2015).

O Brasil atualmente, tem $13,55 \%$ de sua população acima dos 60 anos. As projeções do IBGE para daqui a 42 anos, é uma inversão no quadro populacional entre jovens e idosos, em 2060 o Brasil terá um quarto do conjunto de habitantes além dos 65 anos de idade e 32,6\% terão mais de 60 anos, ao mesmo tempo que os indivíduos com menos de 25 anos consistirá em apenas $25,34 \%$. Os dados estão representados no gráfico 1 abaixo (LEAL, 2018).

Gráfico 1 - População idosa no Brasil.

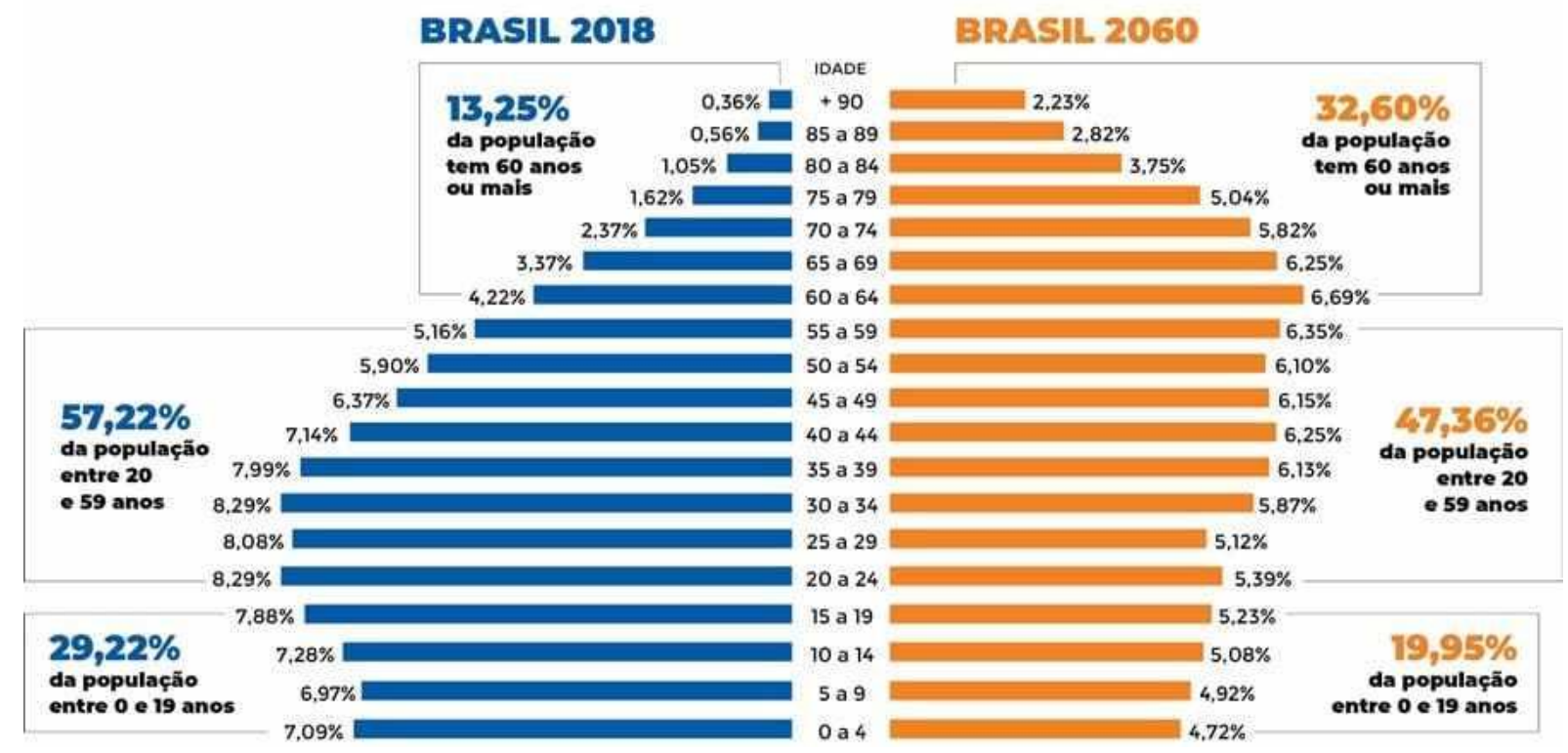

Fonte. Leal, 2018.

O pressuposto para 2020 é de que $15 \%$ da população do Brasil será composta por idosos, crescerá 16 vezes até 2025, classificação em sexto lugar no ranking mundial a respeito da população da terceira idade (CARRETA et al., 2013 e ARAUJO NETO et al., 2017). 
Diante da realidade brasileira, de que os idosos estão vivendo mais tempo, é extremamente importante que a família ofereça o suporte necessário para que esta população tenha uma vida digna.

Há que se concordar com Bertolin e Viecili (2014), quando afirmam que os familiares são os únicos com quem a pessoa possa contar, a partir de sua natividade, referenciando, socializando e efetivando fortes ligações, esses vínculos são encarregados pela estabilidade física, psíquica e afetiva e na carência ou quebra desses elos, surge um vago, um sentimento de desproteção, fragilidade e abjuração.

Abandono é definido como a falta do zelo fundamental à vítima, praticado pelo incumbido em dispor cuidados ou tutela. No entanto, esse tipo de agressão ao idoso, não se trata exclusivamente na utilização de força bruta, mas sim em abandono, utilização de palavras e ações que geram dor e diversas sequelas, seja por ação de membro familiar ou pessoas que criaram laços com a vítima. (MENEZES JUNIOR et al., 2016).

A família é marcada pelos fatores essenciais de afeição, empenho, solidariedade, e apoio durante a vida, além da extensão dos laços afetivos, intelectivos e sociais e da segurança de apresentar-se protegido, apreciado, o que provavelmente explique as diferenças dadas pelos idosos sobre familiares e família (PERSEGUINO et al., 2017).

Os vínculos afetivos e a obrigação social dos membros da família em se apoiarem são aspectos aguardados pelos idosos, que acreditam que toda população mantém essa tradição. O suporte da família é uma condição fundamental para o envelhecimento sadio, que se apresenta em idosos mantidos em cuidados acrescidos de humanização.

O desamparo familiar ocorre inclusive pelo cuidador, independentemente de este não ser familiar. Nascimento; Figueiredo (2019), ressalta que o abandono dos familiares confere ao familiar cuidador, perda da liberdade perante o distanciamento e nos desentendimentos da família ocorridos por questões de enfermidades e debilidade do 
idoso. Além disso, se observa o surgimento de possíveis conflitos entre os familiares, o que torna o trabalho do cuidador árduo.

\subsubsection{ATUAÇÃO DO ENFERMEIRO DIANTE DO IDOSO EM SITUAÇÃO DE ABANDONO}

Se faz imprescindível que o enfermeiro, profissional de maior proximidade ao paciente, tenha conhecimento técnico-científico acerca da gerontologia e das necessidades de cuidado do idoso, que necessita de cuidados hospitalares específico. Compete a equipe de enfermagem apreciar a relevância de acompanhantes no decorrer da internação e procedimentos realizados no idoso, proporcionando melhorias na condição afetiva do idoso (SANGUINO et al. 2018).

Campos (2016), quando o idoso atinge a idade de 80 anos, os muitos que não têm um cuidador específico, faz com que seja alta a dificuldade em se encontrar idosos saudáveis no nosso país, mesmo considerando a autonomia dos idosos nas suas atividades diárias.

Em estudo realizado por Nunes; Pacheco (2018) buscou entender como as agressões ao idoso podem prejudicar o estado de saúde ou doença, destacando os idosos em vulnerabilidade social, foram os que mais sofreram abandono e negligência e mesmo assim, estes indivíduos não se sentiram lesados. Os idosos estudados eram portadores de ao menos duas doenças, sendo uma crônica, advinda de agressão física ou em virtude do abandono e outras por falta de cuidado continuado.

$\mathrm{Na}$ literatura, os estudos apontam o abandono familiar como um agregado do desleixo aos idosos. Sendo assim, identificar este tipo de violência, traz uma ocasião favorável para aperfeiçoar o ato de cuidar. Porém, não se trata de tarefa das mais fáceis, visto que um dos empecilhos de enfrentar esse problema é a limitada inclusão entre os sistemas de saúde e os de paládio de idosos. Diante disso, é imprescindível a capacitação das equipes de enfermagem para constatar, socorrer e advertir as ocorrências de agressões que se apresentam no SUS, a fim de se obter recursos necessários para proteger os idosos (LINO et al., 2019). 
A experiência da enfermagem que atua com a população idosa é fundamental e deve ser amplificada, pois trata-se de especialistas no cuidado ao idoso. A doença e a dependência de pessoas idosas trazem uma reflexão nos enfermeiros sobre sua prática profissional e o aumento da sua compaixão. Assim, entende-se que os enfermeiros necessitam ser cada vez mais capacitados para encarar a individualidade e enredo no cuidado ao idoso (SOUSA; RIBEIRO, 2013).

Sousa; Ribeiro (2013) afirma que dentre a especificidade no cuidado ao idoso, salvaguarda que os enfermeiros sejam amplamente qualificados para atenderem complicadas situações, seja de abusos, problemas de urgência, emergência ou psicossociais.

Os cuidados prestados pela equipe de enfermagem ao idoso que se encontra internado, enfrenta diversos problemas e obstáculos, pois seguem intervenções focadas apenas nas características distintas da senilidade; e cuidados que visam a praticidade facilitada. É necessária uma assessoria voltada a particularidade do idoso, prestando atendimento multidisciplinar efetivo a essa população (SANGUINO et al., 2018).

Os profissionais de enfermagem devem ofertar uma assistência diferenciada para a população idosa que se encontra hospitalizada, pautada pelos princípios da humanização, devendo assim observar as suas expectativas, qualidade e humanização do cuidado (SANGUINO et al., 2018).

Um estudo foi realizado com intuito de avaliar a efetividade de uma intercessão de enfermagem, sustentado por programação gestora de estresse e excesso de trabalho do prestador de serviços ao idoso. Foi comprovado que a ferramenta os auxiliou na agilidade do cuidado e principalmente no aprendizado de novas formas de cuidar. Quanto aos enfermeiros o programa permitiu thes inteirar-se dos obstáculos do cuidador e na visualização de possíveis aprimoramentos nas intervenções do cuidado integral ao idoso (VIEGAS et al., 2018). 


\subsubsection{POSICIONAMENTO DO ENFERMEIRO DA ESF FRENTE IDOSO EM VULNERABILIDADE}

Em 21 de setembro de 2017, foi aprovado pelo Ministério da Saúde uma Portaria, que estabelece a revisão de diretrizes para a organização da atenção básica, no âmbito do sistema de saúde pública, PORTARIA N 2.436 (BRASIL, 2017).

Uma política pública de atenção ao idoso, necessita de amplas intervenções pertinente ao envelhecimento. Para OMS trata-se de um assunto de extrema importância, algo vital que é capaz de ser realizado em qualquer circunstância (MUROSINI, 2018)

É esperado que a equipe de enfermagem e demais profissionais competentes, deem ênfase na assessoria integral e constante de todas as famílias ligadas a rede de atendimento público, sem deixar de lado o âmbito familiar e societário (ARAÚJO NETO, 2017).

A equipe de saúde deve atentar-se às variações do contorno habitacional de sua região de cobertura, com realce e foco na população idosa e manter presente uma ação que vise, acolhimento, progresso na vida e saúde dos idosos, restauração de laços afetivos, inserção coletiva e familiar (DENNINGER, 2015).

O profissional de enfermagem deve atuar pautado no acolhimento, pois trabalham no planejamento coeso de solidariedade existencial, favorável a população. Desse modo, é importante haver uma política social que beneficie os idosos durante execução das leis a prováveis desleixos exercidos familiares (CAMACHO et al., 2015).

Todas as equipes de saúde têm o dever de proporcionar uma interação entre família, cuidador e sociedade no processo socioeducativo, para diminuir a negligência enfrentada pela população idosa.

Likes et al (2018) buscaram aprender a aplicação das leis de defesa aos idosos na saúde pública e a entendimento dos funcionários, em especial o enfermeiro, que tem como função a atuação e orientação, sobre os direitos e deveres dessa população. 
Desenvolvem ações a fim de capacitar a percepção de ambos, evitando possíveis problemas futuros e resultando em melhorias significativas ao decorrer da vida do idoso.

Deste modo, buscam os dos profissionais da ESF, um vínculo com o idoso, que respeite sua história de vida, sua real situação e que forneça extrema importância aos sentimentos e dores decorrente das negligências ou abandono familiar. Esse tipo de vínculo tende impulsionar a saúde (CAMACHO et al., 2015).

É imprescindível preparar os profissionais de enfermagem com cursos, aulas e palestras, tornando os aptos a realizar acolhimentos ao idoso em situação de vulnerabilidade, resultante de abandono e agressões familiares. Se deve humanizar o cuidado aos idosos e torna-se necessário, instruir a sociedade quanto aos direitos dos idosos.

Para Camacho et al (2015), é relevante lembrar que a experiência do cuidado gerontológico das enfermeiras em suas atividades nas Unidades da Estratégia de Saúde da Família suplica por verbas dignas de recursos humanos qualificados através de educação permanente, como inclusive disposição de infraestrutura mínima para a execução adequada das atividades.

As políticas públicas atuam na luta contra a violência, tratando esse inconveniente como um problema de saúde pública, conduzindo esse encargo preferencialmente para a enfermagem e posteriormente para demais profissionais e instituições especializadas (CAMACHO et al., 2015).

Nascimento e Figueiredo (2019) realizaram um estudo para conhecer a opinião do cuidador familiar do idoso em estado mental debilitado, a respeito dos cuidados ofertados ao paciente. O conteúdo realça que a equipe de saúde familiar recebe e ampara ambos, no entanto não é apontada como uma referência em qualidade do cuidado. Para os cuidadores familiares, o que aumenta os obstáculos é a condição de desamparo vivenciada. A equipe de saúde familiar até então dispõe de conhecimento básico relacionados as adversidades encontradas pelo idoso, família e pelo cuidador. 
Outro aspecto que deve ser considerado pelo profissional, é a saúde mental do cuidador. Na maioria das vezes, o cuidador se encontra sobrecarregado, ou não possui informações e conhecimentos relevantes do ato de cuidar. O cuidador deve ser informado sobre a relevância do descanso, repouso e entretenimento, e da variação com outros profissionais evitando as sobrecargas e estresse. Desde modo, destacasse a importância que há em aplicar medidas de gerenciamento educacionais direcionados a toda família incluindo os cuidadores.

\section{CONSIDERAÇÕES FINAIS}

É importante lembrar que não somente os filhos empregam o abandono ao idoso, mas sim qualquer pessoa que tenha estabelecido um laço afetivo com a pessoa em estado senil, salientamos a seriedade do compromisso de zelo ao idoso, que necessita ser exercido com amor e empatia. A assistência de Enfermagem ao idoso é indispensável seja em ambiente hospitalar ou residencial, visto que tem por finalidade suprir às necessidades de cuidados básicos e cruciais desse grupo, concedendo-Ihe maior qualidade de vida.

Estes profissionais, através dos cuidados de enfermagem, são capazes de promover ao idoso a concepção de liberdade, dever de atuação, participação e empoderamento de deliberação a respeito de suas imposições de saúde e zelo.

A retomada da ética do ponto de vista quanto senilidade digna transcorre por inúmeras debates na população que envelhece e, principalmente, em meio as equipes de saúde. A enfermagem em particular, tem por obrigação proporcionar uma assessoria humanizada a população idosa, ofertando um cuidado integral e abrangente.

Há que refletir sobre o suporte no cuidado voltado à pessoa na terceira idade. O idoso precisa contar com a possibilidade de que seus familiares tenham também uma estrutura que garanta o cuidar dos mesmos sem colocar em risco a própria sobrevivência. Em síntese, constata-se que a pessoa em estado senil não passa por situação de abandono exclusivamente por maldade, ou por conveniência dos seus familiares, mas porque todos, em suas realidades sociais, dependem de seus próprios 
meios para assegurar não apenas a própria sobrevivência, mas também a sobrevivência do idoso.

\section{REFERÊNCIAS}

ABREU, H.C.A. et al. Incidência e fatores preditores de quedas de idosos hospitalizados. Rev. Saúde Pública. v.49, n.37. 2015.

ARAÚJO NETO, A.H.; PATRÍCIO, A.C.F.; FERREIRA, M.A.C. et al. Quedas em idoso institucionalizados: riscos, consequências e antecedentes. Rev.Bras.Enferm. v.70, n.4, 2017.

BRASIL. Lei no 13.466, de 12 de julho de 2017. Altera os arts. 3o, 15 e 71 da Lei no 10.741, de 10 de outubro de 2003, que dispõe sobre o Estatuto do Idoso e dá outras providências. Diário Oficial da República Federativa do Brasil. Brasília, DF.2017.

BERTOLIN, G.; VIECILI, M. Abandono Afetivo do Idoso: Reparação Civil ao Ato de (não) Amar? Revista Eletrônica de Iniciação Científica. Itajaí, Centro de Ciências Sociais e Jurídicas da UNIVALI. v. 5, n.1, p. 338-360, 2014.

CAMACHO, A.C.L.F.; ALVES, R.R. Maus tratos contra os idosos na perspectiva. Rev. enferm UFPE. Recife. V. 9, n.supl. 2, p. 927-935. 2015.

CARRETTA, M.B.; BETTINELLI, L.A.; ERDMANN, A.L. Reflexões sobre o cuidado de enfermagem e a autonomia do ser humano na condição de idoso hospitalizado. Rev. bras. enferm. v.64, n.5, p.25-29. 2011.

GASPAROTTO, L. P. R.; FALSARELLA, G. R.; COIMBRA, A. M. V. As quedas no cenário da velhice: conceitos básicos e atualidades da pesquisa em saúde. Revista Brasileira de Geriatria e Gerontologia, v.17, n.1, p. 201-209, 2014.

LEAL, P. População idosa cresce, enquanto a d jovens encolhe no Jaraguá do Sul. OCP News. 2018. 
LIKES, S.A. et al. Estatuto do idoso e sua aplicabilidade: o cuidado de enfermagem em uma Estratégia Saúde da Família. Destaques Acadêmicos, Lajeado, v. 10, n. 3, p. 115-127, 2018.

LINO, V.T.S. et al. Prevalência e fatores associados ao abuso de cuidadores contra idosos dependentes: a face oculta da violência familiar. Ciência \& Saúde Coletiva, v.24, n.1, p.87-96, 2019.

LOPES, E.D.S. et al. Maus tratos a idosos. Rev. Bras. Geriatr. Gerontol., Rio de Janeiro. v. 21, n.5, p. 652-662. 2018.

MENEZES JUNIOR, E.E. et al. Caracterização do Abandono Afetivo do idoso e as ações em Anápolis de apoio ao dever da proteção integral: proposta de construção de cartilha informativa à terceira idade. Revista Eletrônica do Curso de Direito - PUC Minas Serro - n.14. p. 84-99. 2016.

MIRANDA, L.C.V.; SOARES, S.M.; SILVA, P.A.B. Qualidade de vida e fatores associados em idosos de um Centro de Referência à Pessoa Idosa. Ciênc. saúde coletiva. v.21, n.11, p.3533-3544. 2016.

MUROSINI, M.V.G.C. Política Nacional de Atenção Básica 2017: retrocessos e riscos para o Sistema Único de Saúde. Saúde debate. v. 42, n. 116, p. 11-24, 2018.

NASCIMENTO, H.G.; FIGUEIREDO, A.E. Demência, familiares cuidadores e serviços de saúde: o cuidado de si e do outro. Ciência \& Saúde Coletiva. v. 24, n.4, p.13811392,2019

OLIVEIRA, M.R.; VERAS, R.P.; CORDEIRO, H.A.; PASINATO, M.T. A mudança de modelo assistencial de cuidado ao idoso na Saúde Suplementar: identificação de seus pontos chave e obstáculos para implementação. Physis v.26, n.4, p.1383-1394. 2016.

PERSEGUINO MG, HORTA ALM, RIBEIRO CA. A família frente a realidade do idoso de morar sozinho. Rev Bras Enferm. v.70, n.2, p.235-241. 2017. 
SANTANA NETO, J. Diagnóstico de enfermagem memória prejudicada em idosos hospitalizados. Acta paul enferm. v.24, n.1, p.:36-42. 2013.

SANGUINO, G.Z.; PREVIATO, G.F.; SILVA, A.F. et al. O trabalho de enfermagem ao idoso hospitalizado. J. res.: fundam. care. v. 10, n.1, p. 160-166. 2018.

SILVA, M.R.F. Envelhecimento e proteção social: aproximações entre Brasil, América Latina e Portugal. Serv. Soc. Soc. N.126, p.215-234. 2016.

SOUSA, L. RIBEIRO, A.P. Prestar cuidados de enfermagem a pessoas idosas: experiências e impactos. Saúde Soc. São Paulo, v.22, n.3, p.866-877, 2013

VERAS, R.P. et al. Desenvolvimento de uma linha de cuidados para o idoso: hierarquização da atenção baseada na capacidade funcional. Revista Brasileira de Geriatria e Gerontologia 2013; 16(2):385-392.

VERAS RP, OLIVEIRA MR. Linha de cuidado para o idoso: detalhando o modelo. Rev. bras. geriatr. gerontol.v. 19, n.6, p.887-905. 2016.

VIEGAS LM, FERNANDES AA, VEIGA MAPL. Intervenção de enfermagem no estresse do cuidador familiar do idoso com dependência: estudo piloto. Rev baiana enferm. v.32, n.:e25244. 2018.

Enviado: Outubro, 2019.

Aprovado: Outubro, 2019. 